\section{Crop Load Adjustment in 'Seyval Blanc' Winegrape: Impacts on Yield Components, Fruit Composition, Consumer Wine Preferences, and Economics of Production}

\author{
Tyler G. Berkey ${ }^{1}$, Anna Katharine Mansfield ${ }^{2}$, Steven D. Lerch ${ }^{3}$, \\ James M. Meyers ${ }^{3}$, and Justine E. Vanden Heuvel $^{3,4}$
}

ADDITIONAL INDEX WORDs. Vitis, cluster thinning, shoot thinning

SumMARY. Crop load management treatments were applied to 'Seyval Blanc' grapevines (Vitis hybrid) as a $2 \times 2$ factorial design: no shoot thinning (ST)/no cluster thinning (CL) (i.e., control), ST combined with CL (ST + CL), ST only, and CL only. All treatments reduced yield and crop load (yield/pruning weight) in 2009 and had a smaller impact in 2010 due to the carryover effect of previous year treatments on crop potential. Soluble solids were improved by up to $3.2 \%$ by the ST + CL treatment in 2009, but were not impacted by treatments in the second year when the range of yield was smaller and the ripening conditions more favorable. Rank sum analysis for the $\mathbf{2 0 0 9}$ vintage indicated that wines produced from the CL treatment were preferred by the sensory panel compared with the control wine, but there were no differences in consumer preference for wines produced in the $\mathbf{2 0 1 0}$ season. Grower preferred price in 2009 (required to compensate the grower for labor costs and lost yield) increased from $\$ 556 / t$ in the control to $\$ 824 / t$ in the $C L$ treatment, an increase which could be justified by the demonstrated consumer preference for the CL wine. Grower preferred price was $\$ 1022 / \mathrm{t}$ in the ST + CL treatment in 2009 , a price increase that was not justified by a demonstrated consumer preference for the wine. In 2010, grower preferred price ranged from $\$ 541 / \mathrm{t}$ for the control to $\$ 610 / \mathrm{t}$ for the $\mathrm{ST}+\mathrm{CL}$ treatment, an unjustified increase based on the lack of demonstrated consumer preference for the wines.

S eyval Blanc' (Seyve-Villard 5$276)$ is a French-American hybrid grape cultivar used in the production of white wines. Because of its cold hardiness and early ripening (Wolf, 2008), 'Seyval Blanc' is grown in such places as the Finger Lakes of New York, Ontario, Canada, and numerous other locations in eastern North America. However, one major detriment of 'Seyval Blanc' is that it has a propensity to overcrop (Reynolds et al., 1986).

Hybrid grapevines often do not respond to balanced pruning techniques like many other grape cultivars

This work was supported by the New York Farm Viability Institute, the New York Wine and Grape Foundation, and Hosmer Winery. We thank Tim Martinson, Bill Wilsey, Luann Preston-Wilsey, and Pamela Raes for their technical assistance, Trent Preszler for contributing expertise toward the economic analysis, and Rebecca Harbut and Terry Bates for assistance with the manuscript.

${ }^{1}$ Department of Horticulture, Cornell University, Ithaca, NY 14853

${ }^{2}$ Department of Food Science, Cornell University, Geneva, NY 14456

${ }^{3}$ Department of Horticulture, Cornell University, Geneva, NY 14456

${ }^{4}$ Corresponding author. E-mail: jev32@cornell.edu. due to fruitful basal buds (Pool et al., 1978) and secondary shoots that are not accounted for in balanced pruning techniques. Consequently, severe dormant pruning generally does not balance excessive fruit production as intended. However, ST is a technique that has been reported to decrease yield and open the canopy to improve the fruit quality of several FrenchAmerican hybrids including 'Marechal Foch' (Sun et al., 2011), 'Seyval Blanc' (Reynolds et al., 1986), as well as Aurore, Chancellor and Villard noir (Morris et al., 2004). It has been suggested that 'Seyval Blanc' vines should be thinned to a density in the range of 12-19 shoots/month of row to obtain a desirable canopy (Reynolds et al., 1986).

Reducing a crop through CL to attain an optimal leaf area to fruit ratio in hybrids has been thoroughly examined (Hummell and Ferree, 1998; Kaps and Cahoon, 1989; Mabe 1983; Morris et al., 1987, 2004; Wolpert et al., 1983). CL generally results in fewer clusters per vine and greater individual cluster weights in hybrids (Reynolds et al., 1986; Wolpert et al., 1983 ) and has been reported to impact various quality metrics in 'Seyval Blanc' (Hummell and Ferree, 1998), 'Vidal Blanc' (Howell et al., 1987; Wolpert et al., 1983), 'Chambourcin' (Prajitna et al., 2007), 'De Chaunac' (Fisher et al., 1977; Reynolds, 1989; Wood and Looney, 1977), and 'Marechal Foch' (Sun et al., 2011).

Although the literature on hybrid wine grapes indicates that crop load management techniques such as ST and CL often improve fruit quality of cultivars prone to overcropping, commercial producers must consider the economic trade-off between implementation costs and potential economic benefits (Preszler et al., 2010). Economic justification for ST and CL is complicated by the fact that grapes of 'Seyval Blanc' and other hybrids generally demand a relatively low price compared with vinifera (Vitis vinifera) cultivars in New York State and elsewhere. As a result, it is important for growers to maintain low production costs and to fully understand the potential economic impact of improving wines through CL and ST (Preszler et al., 2010). The objective of this study was to determine the impact of both CL and ST on yield components, fruit composition, consumer wine preference,

\begin{tabular}{llll}
\hline $\begin{array}{l}\text { Units } \\
\begin{array}{l}\text { To convert U.S. to SI, } \\
\text { multiply by }\end{array}\end{array}$ & U.S. unit & SI unit & $\begin{array}{l}\text { To convert SI to U.S., } \\
\text { multiply by }\end{array}$ \\
\hline 10 & $\%$ & $\mathrm{~g} \cdot \mathrm{L}^{-1}$ & 0.1 \\
0.4047 & $\mathrm{acre}(\mathrm{s})$ & $\mathrm{ha}$ & 2.4711 \\
29.5735 & $\mathrm{fl} \mathrm{oz}$ & $\mathrm{mL}$ & 0.0338 \\
0.3048 & $\mathrm{ft}$ & $\mathrm{m}$ & 3.2808 \\
3.7854 & gal & $\mathrm{L}$ & 0.2642 \\
2.54 & inch(es) & $\mathrm{cm}$ & 0.3937 \\
0.4536 & $\mathrm{lb}$ & $\mathrm{kg}$ & 2.2046 \\
7.4892 & $\mathrm{oz} / \mathrm{gal}$ & $\mathrm{g} \cdot \mathrm{L}^{-1}$ & 0.1335 \\
1 & $\mathrm{Ppm}$ & $\mathrm{mg} \cdot \mathrm{L}^{-1}$ & 1 \\
0.9072 & ton $(\mathrm{s})$ & $\mathrm{t}$ & 1.1023 \\
2.2417 & ton/acre & $\mathrm{t} \cdot \mathrm{ha}^{-1}$ & 0.4461 \\
$\left({ }^{\circ} \mathrm{F}-32\right) \div 1.8$ & ${ }^{\circ} \mathrm{F}$ & $\mathrm{o} C$ & $\left(1.8 \times{ }^{\circ} \mathrm{C}\right)+32$
\end{tabular}


and costs of production of 'Seyval Blanc'.

\section{Method and materials}

Vineyard site. 'Seyval Blanc' vines located at a commercial winery on the west side of Cayuga Lake in Ovid, NY, were subjected to canopy and crop load management treatments from 2008 to 2010 . The vines, grown in silt loam soils (Casenovia silt loam, fine-loamy, mixed active, mesic Oxyaquic Hapludalf), were planted in a north-south orientation with $9 \mathrm{ft}$ between rows and $7 \mathrm{ft}$ between vines and trained to a Scott Henry system (Reynolds and Vanden Heuvel, 2009). Standard pest control procedures for the region were followed (Wolf, 2008).

Experimental Design. Four treatments were implemented as a $2 \times$ 2 factorial design: no ST/no CL (i.e., control), ST combined with CL (ST + CL), ST only, and CL only. Treatments were applied in a randomized complete block design with four replications located in four rows (one replication per row). An experimental unit was 5 four-vine panels (i.e., 20 vines). Two of the middle three panels were randomly selected in each experimental unit for data collection (i.e., eight vines). The ST treatments were conducted when shoots were $\approx 2-5$ inches in length. Shoots were thinned to 15 primary shoots per meter with all secondary, tertiary (Mullins et al., 1992), and noncount shoots (Pool et al., 1978) being removed. CL treatments were implemented when berries were roughly pea-sized. The distal cluster was removed on all shoots containing two or more clusters.

YIELD COMPONENTS. Although crop load management treatments were applied in 2008, all vines in the study were accidently mechanically harvested by the grower; as a result there are no data to report for that year. Vines were harvested individually by hand on 29 Sept. 2009, and 9 Sept. 2010 just before commercial harvest. The cluster number per vine was counted and the yield per vine was measured using a hanging scale (Salter Weigh-Tronix, Fairmont, MN). Cluster weights were determined by dividing the yield per vine by the cluster number per vine. In Jan. 2009 and 2010, vines were pruned according to grower specifications, and prunings were weighed on a per vine basis using a hanging scale. Crop load was determined by dividing yield by pruning weight on a per vine basis for each year [i.e., yield for 2009 divided by pruning weight for 2009 (which was collected in Jan. 2010)] as an indicator of reproductive vs. vegetative growth of the vine within a growing season.

CANOPY ANALYSIS. Enhanced point quadrat analysis [EPQA (Meyers and Vanden Heuvel, 2008)] was used to characterize canopy growth and microclimate in 2010. A narrow metal rod was inserted into the canopy at $20-\mathrm{cm}$ intervals and successive contacts of leaves, clusters and canopy gaps were recorded as the rod was pushed through to the other side of the canopy. Canopy parameters were analyzed by EPQA and Canopy Exposure Mapping Tools version 1.6 (available from J.M. Meyers, Cornell University).

Must Composition. A sample of $\approx 20$ clusters was collected randomly from each data collection panel and the clusters were pressed by hand. Soluble solids were measured by a $\mathrm{r}^{2}$ mini digital refractometer (Reichert, Depew, NY). Must $\mathrm{pH}$ was determined using an Accumet ABI5 + Basic and Biobasic meter (Thermo Fisher Scientific, Waltham, MA). Titratable acidity (TA) was measured using a $10-\mathrm{mL}$ sample of must by autotitration (Digital Buret $^{\mathrm{TM}}$; BrandTech Scientific, Essex, CT) in which $0.1 \mathrm{M}$ sodium hydroxide $(\mathrm{NaOH})$ was titrated to an endpoint of $\mathrm{pH}=8.2$.

Winemaking. All four field replicates for each treatment were combined and the fruit was subdivided into duplicate lots for wine making. Grapes were destemmed, pressed, and the must adjusted to $50-\mathrm{ppm}$ sulfur dioxide $\left(\mathrm{SO}_{2}\right)$. The juice was left to settle for $24 \mathrm{~h}$, and subsequently inoculated with Saccharomyces cerevisiae DV10 (Lallemand, Montreal, Quebec, Canada) and fermented in 5-gal glass carboys at $20{ }^{\circ} \mathrm{C}$ (ambient temperature). Yeast nutrients were added in the following forms and quantities in 2009: $0.3 \mathrm{~g} \cdot \mathrm{L}^{-1}$ GoFerm (Lallemand), $0.3 \mathrm{~g} \cdot \mathrm{L}^{-1}$ diammonium phosphate [DAP (Presque Isle Wine Cellars, North East, PA)], and $0.25 \mathrm{~g} \cdot \mathrm{L}^{-1}$ Fermaid (Lallemand). In 2010, the same amount of GoFerm and Fermaid were added, but juice yeast assimilable nitrogen was assessed by enzymatic analyses using a Chemwell 2910 multianalyzer (Unitech Scientific, HIan Gardens, CA) powered by Chemwell
Manager version 6.3.1.220 (Awareness Technology, Palm City, FL), and was brought up to $200 \mathrm{mg} \cdot \mathrm{L}^{-1}$ using DAP. The wine was fermented to dryness (less than $0.5 \mathrm{~g} \cdot \mathrm{L}^{-1}$ residual sugar). Following fermentation in both 2009 and 2010, $\mathrm{SO}_{2}$ was adjusted, and the wines were cold-stabilized. $\mathrm{SO}_{2}$ levels were measured using the Foss FIASTAR segmented flow instrument (Foss, Eden Prairie, MN), and an appropriate amount of potassium metabisulfite solution (aq.) was added to bring the total free $\mathrm{SO}_{2}$ to 40 ppm before bottling. Wines were stored at $4{ }^{\circ} \mathrm{C}$ in standard, 750-mL glass bottles (antique green; Saint-Gobain, Courbevoie, France) with screwcap closures until sensory evaluation.

Sensory evaluation. For each vintage, wines produced from the four treatments were compared through preference ranking (Kramer, 1956), determining the difference in preferential rank sums between all possible combinations of treatments to overcome the deficiencies of the original method (Joanes, 1985). Sensory panelists were selected from a list of volunteer subjects maintained by the Cornell Enology Extension Laboratory and were selected based on availability and frequency of white wine consumption; in each panel, all but two panelists consumed white wine at least one to three times per month. Wines produced in 2009 were evaluated in Jan. 2011 by 27 panelists ( 12 female, 15 male), ranging in age from 23 to 66 years (mean 39 years). Wines produced in 2010 were evaluated in May 2011 by 26 panelists ( 11 female, 15 male), ranging in age from 24 to 67 years (mean 43 years).

Panelists were seated in sensory booths and were presented with $30-\mathrm{mL}$ samples of each wine served at room temperature in $300-\mathrm{mL}$ tasting glasses labeled with three-digit random numbers and covered with petri dish lids. Wine serving order was randomized within and across participants. Panelists were asked to smell all the samples, then taste them, before indicating preference by ranking wines from 1 (most favored) to 4 (least favored).

Economic analysis. A simple economic analysis was performed to determine the additional price per tonne and cost per $750-\mathrm{mL}$ bottle of wine a producer would need to receive in order for them to maintain the same economic welfare (i.e., revenue per 
hectare or revenue per case) if the ST or CL practices were adopted compared with if they were not. Additional production cost per hectare for each treatment was determined according to White (2008), and then additional production cost per tonne was calculated by dividing the additional production cost per hectare by the yield (tonnes per hectare). Expected revenue per hectare was calculated by multiplying yield (tonnes per hectare) by the average industry price for 'Seyval Blanc' (Finger Lakes Grape Program, 2009, 2010). The grower preferred price per tonne to maintain economic welfare was calculated by dividing the expected revenue per hectare for the control treatment ( $\$ 12,793$ in 2009, \$10,381 in 2010) by the yield (tonnes per hectare) and then adding the additional production cost per tonne. Additional cost per 750-mL bottle of wine was determined by subtracting the average price per tonne from the grower preferred price per tonne for each treatment, and then dividing by 655.2 (the number of $750-\mathrm{mL}$ bottles that can be produced from 1 t of grapes).

STATISTICAL METHODS. Treatment response data were analyzed using the general linear model (GLM) procedure of SAS software (version 9.2; SAS Institute, Cary, NC). Main effect least significant differences (LSD) werecomputed using the GLM LSD procedure $(\alpha=0.05)$. Years were analyzed separately as interactions with year were significant $(P \leq 0.05)$ for many parameters evaluated. Probability values for comparison of treatment means were computed for both main effects and interactions using the GLM LSMEANS procedure. Significance of sensory data was determined using the rank sums critical values tables (Basker, 1988).

\section{Results and discussion}

Yield components. The impact of the crop load management treatments differed between the 2 years of data collection. In 2009, both ST and CL had an impact on yield. Relative to the control, yield was lowered 4.2 $\mathrm{kg} /$ vine by CL, $2.6 \mathrm{~kg} /$ vine by ST, and $5.9 \mathrm{~kg} /$ vine by a combination of ST + CL (Table 1). Furthermore, the cluster number per vine was lowered by these practices compared with the control (Table 1). The average cluster weight of vines subjected to ST was greater than on control vines while CL had no impact on cluster weight

Table 1. Impact of shoot thinning (ST) and cluster thinning (CL) on yield components and pruning weight of 'Seyval Blanc' grapevines in 2009 and 2010. Probability values are presented for treatment main effects (ST and CL) as well as the interaction of the two crop control treatments $(S T \times C L)$.

\begin{tabular}{|c|c|c|c|c|c|}
\hline Treatment $^{\mathrm{z}}$ & $\begin{array}{c}\text { Yield } \\
(\mathrm{kg} / \text { vine })^{\mathrm{y}}\end{array}$ & $\begin{array}{c}\text { Clusters } \\
\text { (no./vine) }\end{array}$ & $\begin{array}{l}\text { Cluster } \\
\text { wt (kg) }\end{array}$ & $\begin{array}{c}\text { Pruning } \\
\text { wt (kg) }\end{array}$ & $\begin{array}{c}\text { Crop load } \\
\text { [yield/pruning } \\
\text { wt (ratio)] }\end{array}$ \\
\hline \multicolumn{6}{|c|}{2009} \\
\hline Control & 13.3 & 88.3 & 0.15 & 0.37 & 48.9 \\
\hline $\mathrm{ST}+\mathrm{CL}$ & 7.4 & 39.6 & 0.19 & 0.61 & 15.2 \\
\hline $\mathrm{CL}$ & 9.1 & 62.9 & 0.15 & 0.64 & 19.1 \\
\hline ST & 10.7 & 62.8 & 0.17 & 0.52 & 29.3 \\
\hline$P$ value for ST & 0.0012 & $<0.0001$ & $<0.0001$ & 0.3067 & 0.0281 \\
\hline$P$ value for $\mathrm{CL}$ & $<0.0001$ & $<0.0001$ & 0.4066 & 0.0024 & $<0.0001$ \\
\hline$P$ value for $S T \times C L$ & 0.4627 & 0.7888 & 0.0593 & 0.1200 & 0.1207 \\
\hline $\mathrm{LSD}^{\mathrm{x}}$ & 1.30 & 7.85 & 0.015 & 0.11 & 9.98 \\
\hline \multicolumn{6}{|c|}{2010} \\
\hline Control & 11.1 & 73.1 & 0.15 & 0.46 & 28.5 \\
\hline $\mathrm{ST}+\mathrm{CL}$ & 10.0 & 55.0 & 0.18 & 0.64 & 21.0 \\
\hline $\mathrm{CL}$ & 12.0 & 85.0 & 0.15 & 0.52 & 27.3 \\
\hline ST & 10.5 & 62.8 & 0.17 & 0.60 & 20.0 \\
\hline$P$ value for ST & 0.0184 & $<0.0001$ & 0.0006 & 0.0997 & 0.0059 \\
\hline$P$ value for CL & 0.3683 & 0.6337 & 0.2097 & 0.1219 & 0.9431 \\
\hline$P$ value for $S \mathrm{~T} \times \mathrm{CL}$ & 0.1330 & 0.0224 & 0.1646 & 0.4093 & 0.7310 \\
\hline LSD & 1.46 & 8.45 & 0.012 & 0.11 & 5.29 \\
\hline
\end{tabular}

${ }^{\mathrm{z}} \mathrm{Control}=$ no ST and no CL, ST $=15$ primary shoots per meter $(4.6$ shoots $/ \mathrm{ft}), \mathrm{CL}=$ distal cluster removed on shoot containing $>2$ clusters.

${ }^{\mathrm{y}} \mathrm{l} \mathrm{kg}=2.2046 \mathrm{lb}$

${ }^{\mathrm{x}}$ Least significant difference $(\alpha=0.05)$.

(Table 1). This is contrary to other results reported for 'Seyval Blanc' in which CL not only lowered the cluster number per vine but also increased cluster weights to the point where yield per vine was not severely impacted (Reynolds et al., 1986). Pruning weights from the 2009 growing season were increased $0.27 \mathrm{~kg} /$ vine by CL (Table 1) but not by ST. This increase in vegetative growth is most likely attributable to a reduction in crop load (Table 1). The ST $\times$ CL interaction was not significant for any yield components in 2009.

In 2010, yield, cluster number, cluster weight, pruning weight, and crop load were not impacted by CL (Table 1). However, ST reduced yield by $0.6 \mathrm{~kg} /$ vine although average cluster weight was increased in that treatment (Table 1). Crop load was reduced by ST as well as the ST + CL treatment, but contrary to the 2009 results crop load was unaffected by CL. The ST $\times$ CL interaction was significant and additive for cluster number per vine (Table 1).

Impact of crop load reduction treatments likely differed between years due to the carryover effects of the treatments applied in 2009, and potentially those applied in 2008 . Control vines had a high crop load in 2009 which reduced the pruning weight (Table 1), and decreased the crop potential for the 2010 growing season (Winkler, 1954). Vines subjected to ST and/or CL maintained higher pruning weights, and therefore, higher crop potential for 2010 (Winkler, 1954). Likely as a result of the 2009 treatments, differences in yield, pruning weight, and crop load among treatments were considerably smaller in 2010 compared with 2009. While yield data from the 2008 growing season is unavailable, it's possible that the effect of the treatments in the 2 years (2008 and 2009) was additive.

ST and CL had few impacts on EPQA metrics in 2010. Occlusion layer number values ranged from 2.2 to 2.4 with no differences among treatments. Cluster exposure layer (CEL), cluster exposure flux availability (CEFA), canopy cluster symmetry (CCS), and cluster exposure flux symmetry (CEFS) were all impacted by treatment. CL resulted in reduced cluster exposure as evidenced by an increase in CEL of 0.30 and a decrease in CEFA of 0.10 when CL was applied (data not shown). ST caused a reduction of 0.28 in CCS 
and a reduction of 0.45 in CEFS (data not shown).

Must Composition. In 2009, soluble solids were increased by $2.1 \%$, $2.3 \%$, and $3.2 \%$ by ST, CL, and ST + CL, respectively (Table 2) compared with the control. This result is in agreement with previous reports that demonstrate the capacity of ST and CL to improve soluble solids in hybrids (Dami et al., 2006; Prajitna et al., 2007; Reynolds et al., 1986; Wolpert et al., 1983). The low soluble solids production by the control treatment suggests that the high crop load in that treatment (Table 1) negatively impacted the ability of the vine to ripen the fruit.

None of the crop load management treatments significantly altered soluble solids in 2010 , likely because yield did not vary greatly among treatments. Furthermore, soluble solids of the fruit were considerably higher in 2010 (average 20.4\%) compared with 2009 (average $17.1 \%$ ), likely as a result of temperature differences between growing seasons. In 2009, 1221 growing degree days (base $10{ }^{\circ} \mathrm{C}$ ) were accumulated from 1 May to 31 Oct. while 1487 GDD were amassed in 2010 [data sourced from the Geneva NY station maintained by the Network for Environment and Weather Applications (2010)].

The fruit $\mathrm{pH}$ in 2009 and 2010 was largely unaffected by the treatments, although the $\mathrm{pH}$ was increased by 0.09 in the $2010 \mathrm{ST}$ treatment (Table 2) compared with the control. In 2009 , TA was increased by $2 \mathrm{~g} \cdot \mathrm{L}^{-1}$ in the ST + CL treatment (Table 2), while the control had the lowest TA of all treatments $\left(7.3 \mathrm{~g} \cdot \mathrm{L}^{-1}\right)$ similar to the result reported by Hummell and Ferree (1998). In 2010, none of the treatments influenced TA. These results for TA are anomalous in contrast to other hybrid studies where TA has been decreased by ST and unaffected by CL (Dami et al., 2006, Morris et al., 1987) or decreased by both ST and CL (Reynolds et al., 1986). Potential explanations for the discrepancy in results between our work and previously published studies include climatic differences among sites/years as well as implications of the high crop loads reported here for 'Seyval Blanc' compared with those in previous work (Reynolds et al., 1986).

WINE SENSORY ANALYSIS. Rank sum analysis for the 2009 vintage indicated that wines produced from the CL treatment were preferred $(P \leq 0.05)$ to the control wine. Wines from the

Table 2. Impact of shoot thinning (ST) and cluster thinning (CL) on must composition of 'Seyval Blanc' grapevines in 2009 and 2010. Probability values are presented for treatment main effects (ST and CL) as well as the interaction of the two crop control treatments $(\mathrm{ST} \times \mathrm{CL})$.

\begin{tabular}{|c|c|c|c|}
\hline Treatment $^{\mathrm{z}}$ & $\mathrm{pH}$ & Soluble solids concn (\%) & TA $\left(g \cdot L^{-1}\right)^{y}$ \\
\hline \multicolumn{4}{|c|}{2009} \\
\hline Control & 3.52 & 15.2 & 7.3 \\
\hline $\mathrm{ST}+\mathrm{CL}$ & 3.60 & 18.4 & 9.3 \\
\hline $\mathrm{CL}$ & 3.61 & 17.5 & 8.2 \\
\hline ST & 3.65 & 17.3 & 7.8 \\
\hline$P$ value for ST & 0.2853 & 0.0163 & 0.0132 \\
\hline$P$ value for CL & 0.6894 & 0.0067 & 0.0011 \\
\hline$P$ value for $\mathrm{ST} \times \mathrm{CL}$ & 0.1851 & 0.2949 & 0.4097 \\
\hline $\mathrm{LSD}^{\mathrm{x}}$ & 0.10 & 1.17 & 0.66 \\
\hline
\end{tabular}

\begin{tabular}{llcl} 
& & 2010 & \\
Control & 3.60 & 20.5 & 5.6 \\
ST + CL & 3.64 & 20.7 & 5.3 \\
CL & 3.62 & 19.8 & 6.0 \\
ST & 3.69 & 20.4 & 5.9 \\
$P$ value for ST & 0.0135 & 0.0936 & 0.4717 \\
$P$ value for CL & 0.5580 & 0.4239 & 0.7146 \\
$P$ value for ST $\times$ CL & 0.1173 & 0.0524 & 0.0609 \\
LSD & 0.05 & 0.49 & 0.47 \\
\hline
\end{tabular}

${ }^{\mathrm{z}} \mathrm{Control}=$ no ST and no CL, ST $=15$ primary shoots per meter $(4.6$ shoots $/ \mathrm{ft}), \mathrm{CL}=$ distal cluster removed on shoot containing $>2$ clusters.

yitratable acidity; $1 \mathrm{~g} \cdot \mathrm{L}^{-1}=0.1 \%$.

${ }^{\mathrm{x}}$ Least significant difference $(\alpha=0.05)$.

ST + CL treatment were ranked second preferentially but were not different from the control; the difference between control and ST + CL rank sums was 23 , but a difference of at least 24.4 was required to indicate significance. Similarly, the rank sum of the third-ranked ST treatment did not differ from that of CL, with a rank sum difference of 23. It seems likely that the cause for similarity in preference for the CL wine, and near preference for ST + CL treatment, is due to the lower crop load in these two treatments.

In contrast, the consumer sensory panel indicated no preferences with respect to wines produced in 2010 , likely since yields ranged by only 2.0 $\mathrm{kg} /$ vine among treatments compared with a range of $5.9 \mathrm{~kg}$ /vine among treatments in 2009, and the range of crop loads was only $8.5 \mathrm{~kg} \cdot \mathrm{kg}^{-1}$ in 2010 compared with $33.7 \mathrm{~kg} \cdot \mathrm{kg}^{-1}$ in 2009 (Table 1). Additionally this difference may be a function of seasonal variation; because 2009 was much cooler and wetter, the physiological differences effected by CL and ST are likely more pronounced than those occurring in a warmer season when further fruit ripening is facilitated by environmental conditions. Di Profio et al. (2011) also reported considerably stronger sensory differences among wines produced from vines subjected to differing viticultural treatments in less favorable growing seasons than in good seasons.

ECONOMIC ANALYSIS. In order for a grower to maintain a similar revenue when they implement these crop load practices compared with when they do not, the respective costs of crop load management treatments must be balanced by charging either a higher market price when grapes or bottles of wine are sold. The average industry price for 'Seyval Blanc' in the Finger Lakes in 2009 and 2010 was $\$ 556.10 / \mathrm{t}$ and $\$ 540.68 / \mathrm{t}$, respectively, as reported by the Finger Lakes Grape Program $(2009,2010)$. While the prices remained close over these two years, impacts of the crop load management treatments on yield and fruit composition were considerably different in 2009 and 2010. This is of particular importance to the economic analysis of crop load management practices because one of the major costs of these practices is due to loss of yield. In 2009 , the yield dropped from $23 \mathrm{t} \cdot \mathrm{ha}^{-1}$ in the control to $12.8 \mathrm{t} \cdot \mathrm{ha}^{-1}$ in the 
Table 3. Cost/return analysis of crop load management practices on 'Seyval Blanc' grapevines in 2009 and 2010. Values were rounded to nearest dollar.

\begin{tabular}{|c|c|c|c|c|c|c|}
\hline Treatment $^{\mathrm{z}}$ & $\begin{array}{l}\text { Additional } \\
\text { production } \\
\text { cost }(\$ / \mathrm{ha})^{\mathrm{y}}\end{array}$ & $\begin{array}{l}\text { Additional } \\
\text { production } \\
\text { cost }(\$ / t)^{y}\end{array}$ & $\begin{array}{l}\text { Yield } \\
\left(\mathrm{t} \cdot \mathrm{ha}^{-1}\right)^{\mathrm{y}}\end{array}$ & $\begin{array}{l}\text { Expected } \\
\text { revenue } \\
(\$ / h a)^{x}\end{array}$ & $\begin{array}{l}\text { Grower preferred } \\
\text { price to maintain } \\
\text { welfare }(\$ / t)^{\mathrm{w}}\end{array}$ & $\begin{array}{c}\text { Additional } \\
\text { cost }(\$ / \text { bottle })^{v}\end{array}$ \\
\hline \multicolumn{7}{|c|}{2009} \\
\hline $\mathrm{ST}+\mathrm{CL}$ & $287^{\mathrm{u}}$ & 22 & 12.8 & 7,118 & 1,022 & 0.71 \\
\hline $\mathrm{CL}$ & $153^{t}$ & 10 & 15.7 & 8,753 & 824 & 0.41 \\
\hline \multicolumn{7}{|c|}{2010} \\
\hline Control & 0 & 0 & 19.2 & 10,381 & 541 & 0.00 \\
\hline $\mathrm{ST}+\mathrm{CL}$ & 287 & 16 & 17.5 & 9,446 & 610 & 0.11 \\
\hline CL & 153 & 7 & 20.8 & 11,246 & 507 & -0.05 \\
\hline ST & 133 & 7 & 18.0 & 9,726 & 584 & 0.07 \\
\hline
\end{tabular}

${ }^{\mathrm{z}}$ Control $=$ no shoot thinning and no cluster thinning, $\mathrm{ST}=$ shoot thinning $[15$ primary shoots per meter $(4.6$ shoots $/ \mathrm{ft})]$, CL $=$ cluster thinning $($ distal cluster removed on shoot containing $>2$ clusters).

y $\$ 1.00 / \mathrm{ha}=\$ 0.4047 /$ acre, $\$ 1.00 / \mathrm{t}=\$ 0.9072 / \mathrm{ton}, \mathrm{l} \mathrm{t} \cdot \mathrm{ha}^{-1}=0.4461$ ton $/$ acre.

${ }^{x}$ Expected revenue a commercial grape grower can expect to receive for 'Seyval Blanc' calculated by multiplying yield by the reported average industry price for 'Seyval Blanc' $(2009=\$ 556.10 / \mathrm{t}, 2010=\$ 540.68 / \mathrm{t})$

"Price per tonne of 'Seyval Blanc' that a commercial grape grower would need to charge to compensate for the two main costs associated with implementing thinning practices: reduced grape yield and additional production costs.

vAdditional cost per bottle produced after implementing thinning practices, if the commercial grower keeps the grapes to make wine instead of selling them at a market price. Assumes $491.4 \mathrm{~L}$ (129.81 gal) of wine (or 655.2 bottles) per tonne of grapes; $\$ 1.00 / 750-\mathrm{mL}(25.4 \mathrm{fl} \mathrm{oz})$ bottle $=\$ 5.047 / \mathrm{gal}$.

"Additional production cost per hectare for ST and CL in vinifera cultivars, estimated from White (2008).

tAdditional production cost per hectare for CL in vinifera cultivars, estimated from White (2008)

sAdditional production cost per hectare for ST in vinifera cultivars, estimated from White (2008).

ST + CL treatment, which caused the grower preferred price per tonne (to maintain a similar revenue per hectare) to dramatically increase from $\$ 556$ in the control to $\$ 1022$ in the $\mathrm{ST}+\mathrm{CL}$ treatment (Table 3 ). Conversely in 2010 , the yield dropped from 19.2 in the control to $17.5 \mathrm{t} \cdot \mathrm{ha}^{-1}$ in the ST + CL treatment, which caused the price to modestly rise from $\$ 54 \mathrm{l} / \mathrm{t}$ to $\$ 610 / \mathrm{t}$ (Table 3). Price increases per $750-\mathrm{mL}$ bottle to cover labor costs as well as lost yield were as high as $\$ 0.71$ per bottle for the ST + CL treatment in 2009 , but only $\$ 0.11$ per bottle for the same treatment in 2010. It is important to note that labor prices presented in Table 3 were estimated for vinifera cultivars (White, 2008), and the true labor cost of crop load management practices in hybrids is likely greater because of larger and denser canopies.

\section{Conclusion}

Yield and cluster number per vine were decreased in 2009 by CL, ST, and ST + CL, but remained largely unaffected in 2010 , likely as a result of the carryover impacts of the 2009 treatments. Similarly, soluble solids were drastically increased in 2009 by CL, ST, and ST + CL, but there was no impact of the crop load management treatments on soluble solids or TA in 2010 as yields and crop loads did not vary greatly among treatments. Although general guidelines for crop load of vinifera in cool climates generally range from 5 to 10 $\mathrm{kg} \cdot \mathrm{kg}^{-1}$ (Wolf, 2008), there are no specific guidelines to help growers determine appropriate crop loads in hybrid species of varying sizes. This study suggests that crop loads of 15$20 \mathrm{~kg} \cdot \mathrm{kg}^{-1}$ can easily be supported in 'Seyval Blanc' without a detrimental impact on fruit composition. Crop loads in the range of $18-25 \mathrm{~kg} \cdot \mathrm{kg}^{-1}$ resulted in high soluble solids and acceptable TA over a 2 -year period in 'Marechal Foch' in the Finger Lakes region of New York State (Sun et al., 2011), while Reynolds et al. (2004) reported average crop loads over a 4-year period of 21-33 and $13-27 \mathrm{~kg} \cdot \mathrm{kg}^{-1}$ that did not detrimentally impact fruit composition in 'Seyval Blanc' and 'Chancellor', respectively, in British Columbia, Canada. A goal of research viticulturists in hybrid-growing regions should be to more accurately define appropriate crop loads for hybrid cultivars.

Panelists evaluating wines from all treatments ranked a crop load management wine as higher than the control wine for preference in 2009, but did not differentiate wines from crop load management treatments based on preferences in 2010 . While a preference for the CL wine was noted in
2009, the price of 'Seyval Blanc' would have to increase from $\$ 556 / \mathrm{t}$ to $\$ 824 / \mathrm{t}$ (an additional cost of $\$ 0.41$ per $750-\mathrm{mL}$ bottle of wine) to compensate the grower for labor costs and lost yield. The price for vines subjected to $S T+C L$ would need to increase to $\$ 1022 / \mathrm{t}$ (an additional cost of $\$ 0.71$ per $750-\mathrm{mL}$ bottle of wine) in order for a grower to be compensated for labor costs and lost yield, and this price would not be justified as sensory panelists did not prefer this wine over the control wine. There were no differences in preference ratings for wines in 2010, suggesting that crop load reduction techniques may only be economically justified if crop load is extremely high (such as in the control treatment in 2009), and/or during poor growing seasons.

\section{Literature cited}

Basker, D. 1988. Critical values of differences among rank sums for multiple comparisons. Food Technol. 42:79-84.

Dami, I., D. Ferree, A. Prajitna, and D. Scurlock. 2006. A five-year study on the effect of cluster thinning on yield and fruit composition of 'Chambourcin' grapevines. HortScience 41:586-588.

Di Profio, F., A.G. Reynolds, and A. Kasimos. 2011. Canopy management and enzyme impacts on Merlot, Cabernet 
franc, and Cabernet Sauvignon. II. Wine composition and quality. Amer. J. Enol. Viticult. 62:152-168.

Finger Lakes Grape Program. 2009. Grape harvest prices 2009. 1 Aug. 2011. <http:// flg.cce.cornell.edu/GrapeHarvestPrices. html>.

Finger Lakes Grape Program. 2010. Grape harvest prices 2010. 1 Aug. 2011. <http:// flg.cce.cornell.edu/GrapeHarvestPrices. html>.

Fisher, K.H., O.A. Bradt, J. Wiebe, and V.A. Dirks. 1977. Cluster-thinning 'De Chaunac' French hybrid grapes improves vine vigor and fruit quality in Ontario. J. Amer. Soc. Hort. Sci. 102:162-165.

Howell, G.S., T.K. Mansfield, and J.A. Wolpert. 1987. Influence of training system, pruning severity and thinning on yield, vine size, and fruit quality of Vidal blanc grapevine. Amer. J. Enol. Viticult. 38:105-112.

Hummell, A.K. and D.C. Ferree. 1998. Interaction of crop level and fruit cluster exposure on 'Seyval blanc' fruit composition. J. Amer. Soc. Hort. Sci. 123:755761.

Joanes, D.N. 1985. On a rank sum test due to Kramer. J. Food Sci. 50:1442.

Kaps, M.L. and G.A. Cahoon. 1989. Berry thinning and cluster thinning influence vegetative growth, yield, fruit composition and net photosynthesis of 'Seyval blanc' grapes. J. Amer. Soc. Hort. Sci. 114:20-24.

Kramer, A. 1956. A quick rank test for significance of differences in multiple comparisons. Food Technol. 10:392.

Mabe, C.L. 1983. Effects of shoot thinning, cluster thinning, training system and maturity on yield and quality of six cultivars of French hybrid wine grapes. Thesis, University of Arkansas, Fayetteville.
Meyers, J.M. and J.E. Vanden Heuvel. 2008. Enhancing the precision and spatial acuity of point quadrat analyses via calibrated exposure mapping. Amer. J. Enol. Viticult. 59:425-431.

Morris, J.R., G.L. Main, and O.L. Oswald. 2004. Flower cluster and shoot thinning for crop control in FrenchAmerican hybrid grapes. Amer. J. Enol. Viticult. 55:423-426.

Morris, J.R., C.A. Sims, R.K. Striegler, S.D. Cackler, and R.A. Donley. 1987. Effect of cultivar, maturity, cluster thinning, excessive potassium fertilization on yield and quality of Arkansas grapes. Amer. J. Enol. Viticult. 38:260-264.

Mullins, M.G., A. Bouquet, and L.E. Williams. 1992. Biology of the grapevine. Cambridge University Press, Cambridge, UK.

Network for Environment and Weather Applications. 2010. Geneva weather station page. 8 Aug. 2011 . <http://newa.cornell. edu/index $\cdot$ php? page $=$ weather - station page $\&$ WeatherStation $=$ gen $>$.

Pool, R.M., C. Pratt, and H.D. Hubbard. 1978. Structure of base buds in relation to yield of grapes. Amer. J. Enol. Viticult. 29: 36-41.

Prajitna, A., I.E. Dami, T.E. Steiner, D.C. Ferree, J.C. Scheerens, and S.J. Schwartz. 2007. Influence of cluster thinning on phenolic composition, resveratrol, and antioxidant capacity in Chambourcin wine. Amer. J. Enol. Viticult. 58:346-350.

Preszler, T., T.M. Schmit, and J.E. Vanden Heuvel. 2010. A model to establish economically sustainable cluster-thinning practices. Amer. J. Enol. Viticult. 61:140146.

Reynolds, A.G. 1989. Impact of pruning strategy, cluster thinning, and shoot removal on growth, yield, and fruit composition of low-vigor De Chaunac vines. Can. J. Plant Sci. 69:269-275.
Reynolds, A.G., R.M. Pool, and L.R. Mattick. 1986. Effect of shoot density and crop control on growth, yield, fruit composition and wine quality of 'Seyval blanc' grapevines. J. Amer. Soc. Hort. Sci. 111:55-63.

Reynolds, A.G. and J.E. Vanden Heuvel. 2009. Influence of grapevine training systems on vine growth and fruit composition: A review. Amer. J. Enol. Viticult. 60:251-268.

Reynolds, A.G., D.A. Wardle, M.A. Cliff, and M. King. 2004. Impact of training system and vine spacing on vine performance, berry composition, and wine sensory attributes of Seyval and Chancellor. Amer. J. Enol. Viticult. 55:84-95.

Sun, Q., G. Sacks, S. Lerch, and J.E. Vanden Heuvel. 2011. Impact of shoot thinning and harvest date on yield components, fruit composition, and wine quality in Marechal Foch. Amer. J. Enol. Viticult. 62:32-41.

White, G.B. 2008. Costs of establishment and production of vinifera grapes in the Finger Lakes region of New York-2007. Cornell Univ. Bul. E.B. 2008-05.

Winkler, A.J. 1954. Effects of overcropping. Amer. J. Enol. Viticult. 5:4-12.

Wolf, T.K. (ed.). 2008. Winegrape production guide for eastern North America. Natural Resources Agr. Eng. Serv., Ithaca, NY.

Wolpert, J.A., G.S. Howell, and T.K. Mansfield. 1983. Sampling Vidal blanc grapes. I. Effect of training system, pruning severity, shoot exposure, shoot origin, and cluster thinning on cluster weight and fruit quality. Amer. J. Enol. Viticult. 34: 72-76.

Wood, D.F. and N.E. Looney. 1977. Some cluster thinning and gibberellic acid effects on juice and wine quality of De Chaunac grapes. Can. J. Plant Sci. 57: 643-646. 